\title{
Medullar protection in endovascular surgery of thoracoabdominal aorta
}

Viader Barraca, I., Vallejo Tarrat, A., Artigas Soler, A., Rosas, M., Hernández, C., Masó, A.

\section{BACKGROUND}

The drainage CSF as a protective medullar measure in the aortic vascular surgery has shown a reduction in the incidence of medullar ischaemia increasing the medullar perfusion by decreasing intrathecal pressure.

\section{CASE REPORT}

A 68-year-old male patient, with an asymptomatic thoracoabdominal aneurism

\section{Surgery 1}

- Programmed endovascular repair by a fenestrated endograft

- No focal neurological deficiencies at the end of the surgery

- In the recovery room the patient complained about a motor weakness in the lower extremities

\section{Surgery 2}

- High suspicion of medullar ischaemia $\rightarrow$ intradural catheter is used to drain CSF

- Total resolution of the neurologic symptoms

\section{Surgery 3}

- Days after, he complained of progressive interescapular pain

- Angio TC: aortic dissection type B with extension until the proximal end of the aortic endograft

- Differed stent-graft placement

- Before the surgery a lumbar catheter to drain CSF is placed

-Postoperative period without complications
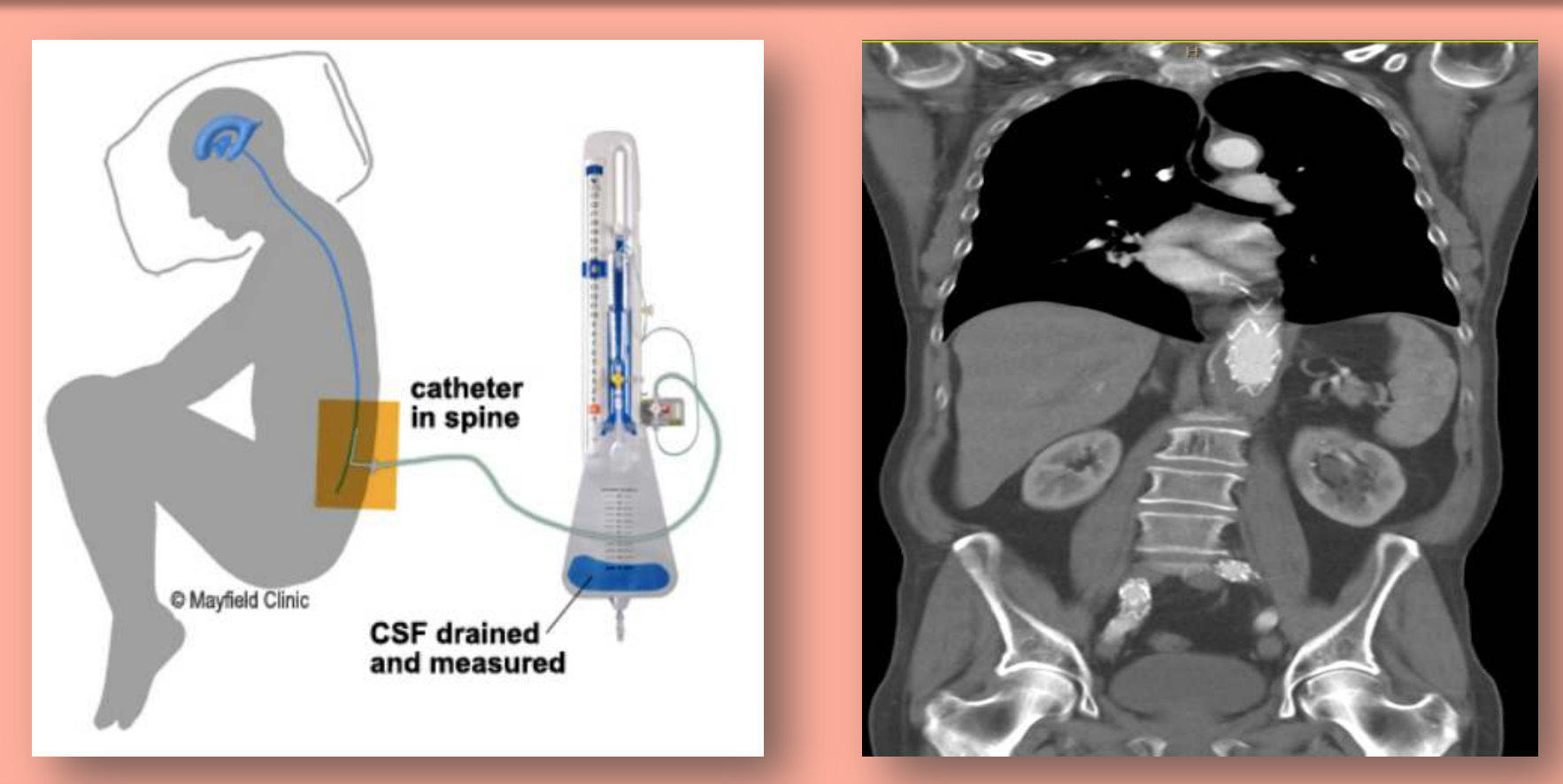

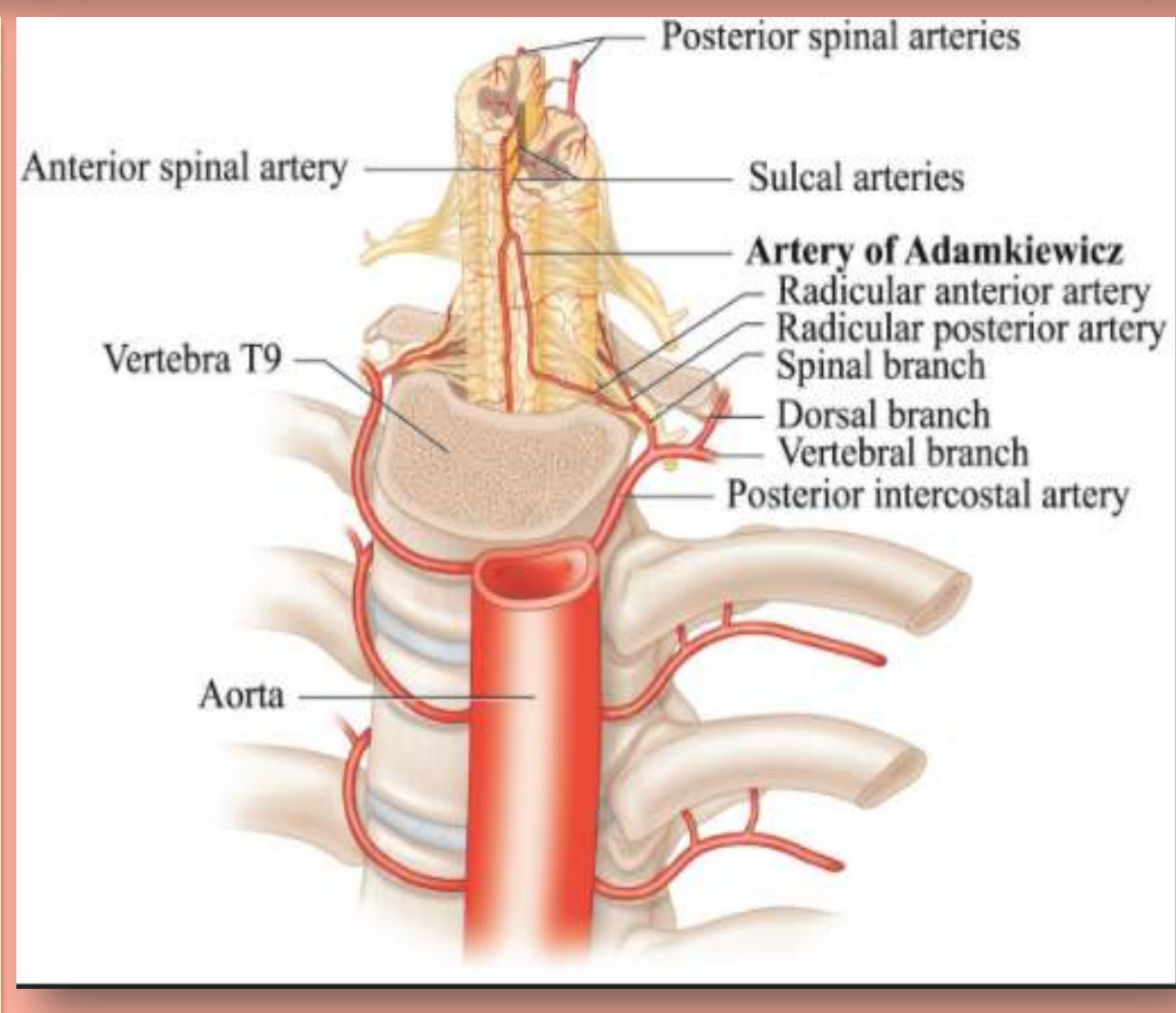

\section{DISCUSSION}

Spinal chord injury is uncommon after FEVAR. The role of prophylactic CSF drainage is difficult to establish from the available literature.

The indications of CSF drainage includes:

- patients with previous aortic endovascular surgery

- subclavic oclusion

- hypogastric oclusion

- long endograft extension.

Our patient had no criteria to place a prophylactic catheter in the first surgery, but due to the neurological complications it was used as a rescue mesure.

\section{LEARNING POINTS}

Although the role of CSF drainage as a medullar protection is not established as a gold standard in thoracoabdominal endovascular surgery, its application in selected cases can be very useful, being one of the fundamental pillars in the prevention and treatment of medullar ischaemia.

-Early experience with automatic pressure-controlled cerebrospinal fluid drainage during thoracic endovascular aortic repair, Kotelis D, Bianchini C, Kovacs B, Müller T, Bischoff M, Böckler . J EndovasC Ther. 2015 Jun; 22 (3): $368-72$ 